OPEN ACCESS

Edited by:

Amit K. Tiwari,

University of Toledo, United States

Reviewed by:

Angelique Nyinawabera,

L.E.A.F. Pharmaceuticsls,

United States

Andaleeb Sajid,

Yale University, United States

*Correspondence:

Jing $L i$

Lijingtiger@163.com

Xiang-Qi L

drlixqi@hotmail.com

Zhe-Sheng Chen

chenz@stjohns.edu

tThese authors have contributed equally to this work

Specialty section:

This article was submitted to Pharmacology of Anti-Cancer Drugs,

a section of the journal

Frontiers in Oncology

Received: 16 April 2020 Accepted: 15 June 2020

Published: 23 July 2020

Citation:

Zhang $M$, Chen $X-Y$, Dong $X-D$, Wang J-Q, Feng W, Teng $Q-X$, Cui $Q$,

Li J, Li X-Q and Chen Z-S (2020) NVP-CGM097, an HDM2 Inhibitor, Antagonizes ATP-Binding Cassette

Subfamily B Member 1-Mediated Drug

Resistance. Front. Oncol. 10:1219.

doi: 10.3389/fonc.2020.01219

\section{NVP-CGM097, an HDM2 Inhibitor, Antagonizes ATP-Binding Cassette Subfamily B Member 1-Mediated Drug Resistance}

\author{
Meng Zhang ${ }^{1,2 \dagger}$, Xuan-Yu Chen ${ }^{2,3 \dagger}$, Xing-Duo Dong ${ }^{2}$, Jing-Quan Wang ${ }^{2}$, Weiguo Feng ${ }^{2,4}$, \\ Qiu-Xu Teng ${ }^{2}$, Qingbin Cui ${ }^{2}$, Jing Li ${ }^{3 *}$, Xiang-Qi Li ${ }^{5 *}$ and Zhe-Sheng Chen ${ }^{2 *}$
}

\begin{abstract}
${ }^{1}$ First Clinical College, Shandong University of Traditional Chinese Medicine, Jinan, China, ${ }^{2}$ Department of Pharmaceutical Sciences, College of Pharmacy and Health Sciences, St. John's University, Queens, NY, United States, ${ }^{3}$ College of Integrated Chinese and Western Medicine, Hebei Medical University, Shijiazhuang, China, ${ }^{4}$ College of Bioscience and Technology, Weifang Medical University, Weifang, China, ${ }^{5}$ Department of Breast Surgery, The Second Affiliated Hospital of Shandong First Medical University, Tai'an, China
\end{abstract}

Multidrug resistance (MDR) is a major challenge in the treatment of tumors. It refers to cancer cells become resistant to not only the therapeutic drug, but also cross-resistant to multiple drugs with distinct structures and mechanisms of action when they are exposed to a drug for a period of time. An essential mechanism of MDR is the aberrant expression and function of ATP-binding cassette (ABC) transporters. Therefore, blocking the function of $\mathrm{ABC}$ transporters has the therapeutic potential in reversing MDR. The hdm2 oncogene product, HDM2 (also known as MDM2), is an important negative regulator of the p53 tumor suppressor. NVP-CGM097 is an HDM2 inhibitor that can inhibit the proliferation of tumor cells and is currently under clinical trials. In this study, we evaluate whether NVP-CGM097 could reverse ABCB1-mediated MDR. The results of reversal experiment showed that NVP-CGM097 remarkably reversed ABCB1-mediated MDR but not ABCG2-mediated MDR. The results of Western blot and immunofluorescence suggested that the level of expression and subcellular localization of ABCB1 protein were not significantly altered by NVP-CGM097. Mechanism studies indicated that NVP-CGM097 could reverse ABCB1-mediated MDR by directly blocking the $A B C B 1-m e d i a t e d$ drug efflux and raising the accumulation of chemotherapeutic drugs in cancer cells. ATPase analysis showed that low concentration NVP-CGM097 activates ABCB1 ATPase activity while high concentration NVP-CGM097 inhibited ABCB1-associated ATPase. Docking study indicated that NVP-CGM097 tended to bind to the inhibitory site, which led to slight but critical conformational changes in the transporter and reduced the ATPase activity. Overall, our study demonstrates that NVP-CGM097 can be used in conjunction with chemotherapeutic drugs to counteract MDR and improve the antitumor responses.

Keywords: ABCB1, multidrug resistance, ABC transporter, NVP-CGM097, chemotherapy 


\section{INTRODUCTION}

Malignant tumors pose a significant hazard to human life and each year the number of deaths caused by malignant tumors ranks first among all forms of diseases (1). Chemotherapy has been one of the important modalities for the treatment of malignant tumors. However, the phenomenon of multidrug resistance (MDR) of tumor cells is the main reason for the failure of chemotherapy $(2,3)$. MDR refers to the drug resistance of tumor cells to multiple antineoplastic drugs with different structures and mechanisms of actions (4). While the mechanism of MDR is complicated, the up-regulation and gainof-function of ATP binding cassette (ABC) transporters is one of the important factors leading to MDR. ABC transporters constitute the largest superfamily of human cellular membrane transporters. It is divided into 7 subfamilies (ABCA $\sim A B C G$ ) based on gene homology and structural similarity (5). Among them, ABCB1 (P-gp/MDR1) and ABCG2 (BCRP/MXR/ABCP), as well as ABCCs (MRPs) have been extensively reported to be associated with MDR (6). Previous studies have reported that overexpression of $\mathrm{ABCB} 1$ is found in many tumors, such as gastric cancer (7), lung cancer (8), breast cancer (9), bladder cancer (10), prostate cancer (11), and so forth. It is also confirmed that the level of ABCB1 is strongly correlated with the chemosensitivity of tumors (12). Consequently, the overexpression of $\mathrm{ABCB} 1$ is an significant factor initiating the development of MDR and leading to the ineffectiveness of chemotherapy (13). Upon reaching the tumor cells, chemotherapeutic drugs first bind to ABCB1, then ATP hydrolysis generates energy for pumping the drugs out of the cells, decreasing the concentration of intracellular drugs, and therefore leading to drug resistance (14-16). Therefore, it is of great significance to develop a treatment option to reverse the MDR mediated by ABCB1.

HDM2 inhibitors are developed to inhibit HDM2-p53 interaction and thereby suppress $\mathrm{p} 53$ deterioration and reactivate the expression of wild-type p53. These inhibitors were under evaluation in clinical trials in adult patients with selected advanced solid tumors (17). Previous studies have shown that there is a synergistic effect between HDM2 inhibitors and ABCB1 substrates (18-20), but the mechanism related to the functional change of $\mathrm{ABCB} 1$ remains unknown. No direct interaction between HDM2 inhibitors and $\mathrm{ABC}$ transporters has been reported to date. In this study, we evaluated a novel HDM2inhibitor NVP-CGM097 (17, 21, 22) against ABCB1-mediated MDR. Our results showed that NVP-CGM097 could reverse ABCB1-mediated MDR at non-cytotoxic concentration.

\section{MATERIALS AND METHODS}

\section{Chemicals}

NVP-CGM097 was a gift from ChemieTek (Indianapolis, IN). DMEM, penicillin/streptomycin, and fetal bovine serum (FBS) were purchased from Corning Incorporated (Corning, NY, USA). Doxorubicin, paclitaxel, cisplatin, mitoxantrone, verapamil, 3-(4,5-dimethylthiazol-yl)-2,5-diphenyltetrazolium bromide (MTT), dimethylsulfoxide (DMSO), Triton X-100, the monoclonal mouse antibodies against $\mathrm{ABCB} 1$ (clone F4, Cat \# SAB4200775), were products from Sigma-Aldrich (St. Louis, MO, USA). The Horseradish peroxidase (HRP)-conjugated rabbit anti-mouse IgG secondary antibody (Cat \# 7076S, lot \#: 32) was obtained from Cell Signaling Technology Inc. (Danvers, MA, USA). The Alexa Fluor 488 conjugated goat anti-mouse IgG cross-adsorbed secondary antibody $(2 \mathrm{mg} / \mathrm{mL}$, Cat \# A32723) and the GAPDH loading control monoclonal mouse antibody (GA1R) (1 mg/mL, Cat \# MA5-15738, lot \#: SA247966) were purchased from Thermo Fisher Scientific Inc. (Rockford, IL, USA).

\section{Cell Lines and Cell Culture}

The human epidermoid carcinoma KB-3-1 cell line and its colchicine-selected ABCB1-overexpressing KB-C2 cell line (23, 24), the human colon cancer SW620 cell line and its doxorubicinselected ABCB1-overexpressing SW620/Ad300 cell line were used for ABCB1 reversal study (25). The non-small cell lung cancer (NSCLC) cell line NCI-H460 and its mitoxantroneselected ABCG2-overexpressing NCI-H460/MX20 cell line were used for ABCG2 reversal study (26). HEK293/pcDNA3.1 and the ABCB1-transfected HEK293 cells (HEK293/ABCB1) were human embryonic kidney HEK293 cells transfected with empty vector pcDNA3.1 and full length ABCB1, respectively, (27). All of the drug-resistant samples were cultivated for at least 2 weeks before use in a medium without drugs.

\section{Cytotoxicity Assay}

The cells in logarithmic growth phase were collected and seeded in 96-well plates with a concentration of 5,000 to 6,000 cells per well. After the cells were incubated overnight, NVP-CGM097 and a parallel control inhibitor of transporter were added $2 \mathrm{~h}$ prior. A chemotherapeutic drug was then added into the designated wells by in a concentration range. After $72 \mathrm{~h}$ of culture, 20 $\mu \mathrm{l}$ of MTT reagent $(0.4 \mathrm{mg} / \mathrm{ml})$ was added to each well and incubated in the incubator for $4 \mathrm{~h}$, then the drug solution was discarded and DMSO solution was added. After gently oscillating $10 \mathrm{~min}$ on the microplate oscillator, the absorbance was measure at $570 \mathrm{~nm}$ in a Spectrophotometer (Fisher Sci., Fair Lawn, NJ, USA) with accuSkan ${ }^{\text {TM }}$ GO UV/Vis Microplate (Fisher Sci., Fair Lawn, NJ, USA).

\section{Western Blotting Analysis}

The Western blotting protocol has been stated in previous study (28). Cells were treated with or without NVP-CGM097 ( $3 \mu \mathrm{M})$ for different time periods $(0,24,48,72 \mathrm{~h})$, and cells were lysed after being washed twice with ice-cold PBS. Concentrations of proteins were calculated using Pierce ${ }^{\mathrm{TM}}$ BCA Protein Assay Kit (Thermo Scientific, Rockford, IL, USA). The total protein was then resolved by gel electrophoresis $(25 \mu \mathrm{g} / \mathrm{lane})$. The protein was transferred to the activated PVDF membrane and blocked by $5 \%$ non-fat milk. The membrane was incubated in monoclonal primary mouse antibodies against GAPDH (1:1000) or ABCB1 (1:1000) overnight, and then followed by incubation with HRPconjugated rabbit anti-mouse IgG secondary antibody (1:1000) for $1 \mathrm{~h}$. ECL chemiluminescence kit was used and the signal was captured by X-ray film. 


\section{Immunocytochemistry}

Immunocytochemistry was carried out as documented in the previous researches (29). KB-3-1 and KB-C2 cells $\left(1 \times 10^{4} /\right.$ well $)$ were seeded into 24 -well plates and incubated for $24 \mathrm{~h}$, followed by incubation with $0.3 \mu \mathrm{M}$ NVP-CGM097 for $0,24,48$, and $72 \mathrm{~h}$. The fixation was performed for $15 \mathrm{~min}$ with $4 \%$ formaldehyde,<smiles>COc1cc2c(cc1OC(C)C)[C@H](c1ccc(Cl)cc1)N(c1ccc(N(C)C[C@H]3CC[C@H](N4CCN(C)C(=O)C4)CC3)cc1)C(=O)C2</smiles>

\section{B}
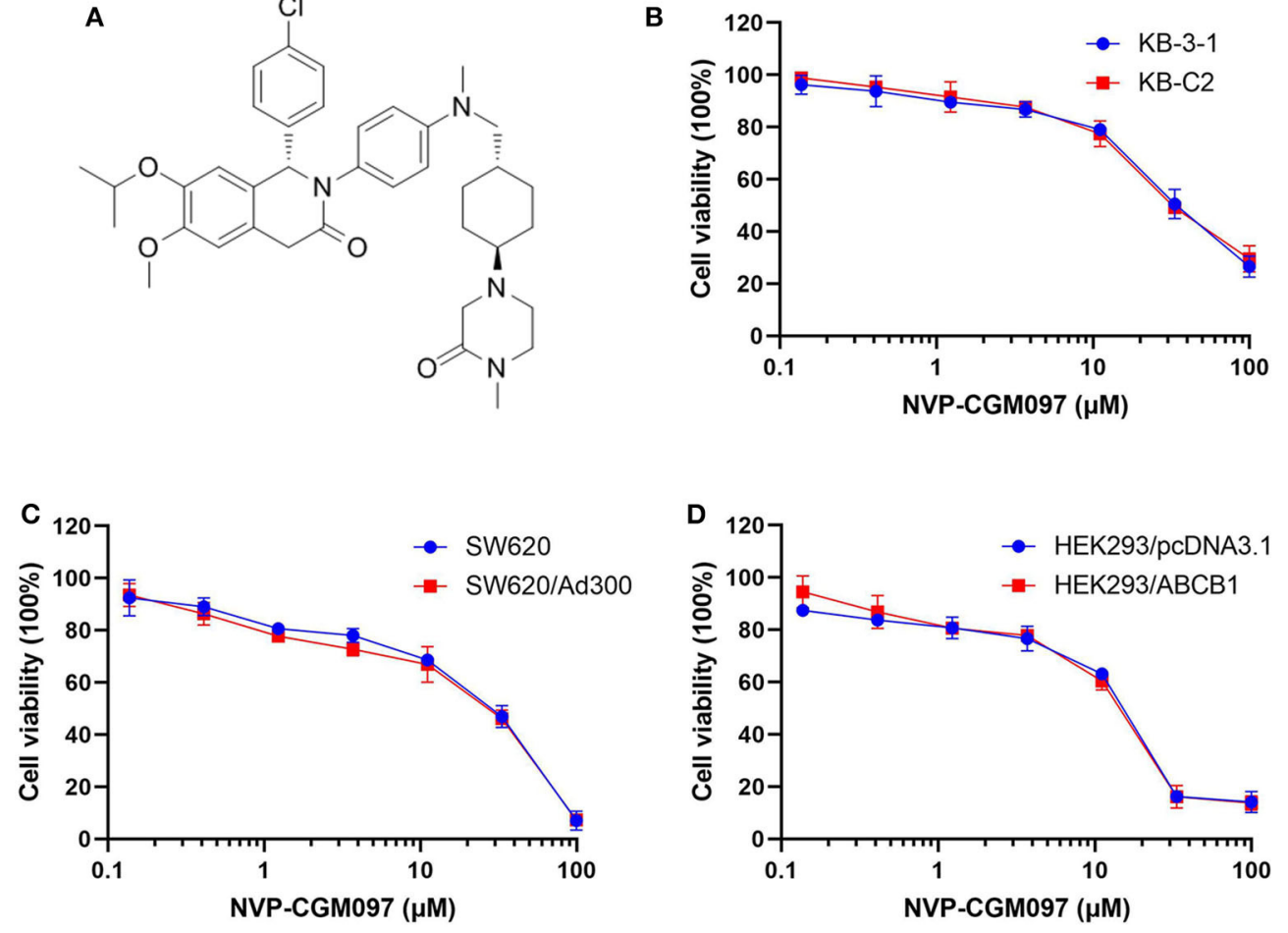

FIGURE 1 | Chemical structure of NVP-CGM097 and concentration-dependent viability curves for parental and ABCB1-overexpressing cells incubated with NVP-CGM097. (A) Chemical structure of NVP-CGM097. (B) Cytotoxicity curves for KB-3-1 and KB-C2 cells incubated with NVP-CGM097 for 72 h. (C) Cytotoxicity curves for SW620 and SW620/Ad300 cells incubated with NVP-CGM097 for 72h. (D) Cytotoxicity curves for HEK293/pcDNA3.1 and HEK293/ABCB1 cells incubated with NVP-CGM097 for $72 \mathrm{~h}$. The cell viability was determined by MTT assay. Data are expressed as mean \pm SD, and representative of three independent experiments in triplicate are shown.

TABLE 1 | NVP-CGM097 sensitized ABCB1-substrate-selected resistant cells to ABCB1 substrates.

\begin{tabular}{|c|c|c|c|c|}
\hline Treatment & \multicolumn{4}{|c|}{$\mathrm{IC}_{50} \pm \mathrm{SD}^{\mathrm{a}}\left(\mathrm{RF}^{\mathrm{b}}\right)(\mu \mathrm{M})$} \\
\hline Doxorubicin & $0.232 \pm 0.034(1.00)$ & $19.687 \pm 0.711(84.86)$ & $0.011 \pm 0.001(1.00)$ & $1.575 \pm 0.477(143.18)$ \\
\hline +NVP CGM097 (1 $1 \mu \mathrm{M})$ & $0.307 \pm 0.033(1.32)$ & $6.831 \pm 1.030(29.44)^{\star}$ & $0.011 \pm 0.002(1.00)$ & $0.344 \pm 0.082(31.27)^{\star}$ \\
\hline +NVP CGM097 $(3 \mu \mathrm{M})$ & $0.215 \pm 0.018(0.92)$ & $1.462 \pm 0.212(6.30)^{*}$ & $0.012 \pm 0.001(1.09)$ & $0.047 \pm 0.007(4.27)^{\star}$ \\
\hline +Verapamil $(3 \mu \mathrm{M})$ & $0.222 \pm 0.022(0.95)$ & $1.511 \pm 0.087(6.51)^{\star}$ & $0.013 \pm 0.001(1.18)$ & $0.065 \pm 0.027(5.91)^{\star}$ \\
\hline +NVP CGM097 (3 $3 \mu \mathrm{M})$ & $0.237 \pm 0.02(1.08)$ & $0.843 \pm 0.32(3.83)^{\star}$ & $0.014 \pm 0.001(0.88)$ & $0.021 \pm 0.018(1.31)^{\star}$ \\
\hline +Verapamil $(3 \mu \mathrm{M})$ & $0.206 \pm 0.07(0.94)$ & $0.957 \pm 0.12(4.35)^{\star}$ & $0.015 \pm 0.001(0.94)$ & $0.032 \pm 0.002(2.00)^{\star}$ \\
\hline Cisplatin & $1.021 \pm 0.112(1.00)$ & $1.109 \pm 0.113(1.09)$ & $1.259 \pm 0.104(1.00)$ & $1.091 \pm 0.071(0.87)$ \\
\hline +NVP CGM097 $(1 \mu \mathrm{M})$ & $1.093 \pm 0.093(1.07)$ & $1.237 \pm 0.101(1.21)$ & $1.206 \pm 0.196(0.96)$ & $1.173 \pm 0.091(0.93)$ \\
\hline +NVP CGM097 (3 $3 \mu \mathrm{M})$ & $1.236 \pm 0.094(1.21)$ & $1.117 \pm 0.122(1.09)$ & $1.096 \pm 0.016(0.87)$ & $1.242 \pm 0.109(0.99)$ \\
\hline
\end{tabular}

a/C50 values were determined by MTT assay as described in "Materials and Methods," and were obtained from three independent experiments in triplicate.

${ }^{b}$ Resistance fold (RF) was calculated from dividing the IC50 values of resistant cells (SW620/Ad300 and KB-C2) by the IC50 of parental cells (SW620 and KB-3-1) in the presence or absence of NVP-CGM097 or positive control inhibitor.

${ }^{*} p<0.05$ vs. group treated with antineoplastic drug only. 
followed by permeabilization for $15 \mathrm{~min}$ with $0.25 \%$ Triton $\mathrm{X}-100$, then blocked for $1 \mathrm{~h}$ with $6 \%$ BSA. The cells were then treated with monoclonal primary mouse antibody against ABCB1 (1:1000) overnight at $4{ }^{\circ} \mathrm{C}$, then with secondary goat anti-mouse IgG antibody combined with Alexa Fluor 488. DAPI was used to counterstain the nuclei. A Nikon TE-2000S microscope (Nikon Instruments Inc., Melville, NY, USA) was used to conduct microscopy.

\section{ATPase Assay}

The vanadate-sensitive ABCB1 ATPase activity is examined using the Pgp-Glo ${ }^{\mathrm{TM}}$ assay system (Promega, Madison, WI, USA)

TABLE 2 | NVP-CGM097 sensitized ABCB1-gene-transfected cells to ABCB1 substrates.

\begin{tabular}{lcc}
\hline Treatment & \multicolumn{2}{c}{ IC $_{50} \pm \mathbf{S D}^{\mathbf{a}}\left(\mathbf{R F}^{\mathbf{b}}\right)(\boldsymbol{\mu} \mathbf{M})$} \\
\cline { 2 - 3 } & HEK293/pcDNA3.1 & HEK293/ABCB1 \\
\hline Doxorubicin & $0.012 \pm 0.004(1.00)$ & $0.289 \pm 0.081(24.08)$ \\
+NVP CGM097 $(1 \mu \mathrm{M})$ & $0.014 \pm 0.004(1.17)$ & $0.123 \pm 0.017(10.25)^{*}$ \\
+NVP CGM097 $(3 \mu \mathrm{M})$ & $0.017 \pm 0.014(1.42)$ & $0.043 \pm 0.004(3.58)^{*}$ \\
+Verapamil $(3 \mu \mathrm{M})$ & $0.015 \pm 0.003(1.25)$ & $0.066 \pm 0.002(5.50)^{*}$ \\
Paclitaxel & $0.016 \pm 0.004(1.00)$ & $0.865 \pm 0.260(54.06)$ \\
+NVP CGM097 $(1 \mu \mathrm{M})$ & $0.020 \pm 0.009(1.25)$ & $0.211 \pm 0.028(13.19)^{*}$ \\
+NVP CGM097 $(3 \mu \mathrm{M})$ & $0.014 \pm 0.004(0.88)$ & $0.025 \pm 0.002(1.56)^{*}$ \\
+Verapamil $(3 \mu \mathrm{M})$ & $0.019 \pm 0.001(1.19)$ & $0.030 \pm 0.002(1.88)^{*}$ \\
Cisplatin & $1.228 \pm 0.093(1.00)$ & $1.184 \pm 0.133(0.96)$ \\
+NVP CGM097 $(1 \mu \mathrm{M})$ & $1.364 \pm 0.098(1.11)$ & $1.213 \pm 0.067(0.99)$ \\
+NVP CGM097 $(3 \mu \mathrm{M})$ & $1.104 \pm 0.164(0.90)$ & $1.025 \pm 0.039(0.83)$ \\
+Verapamil $(3 \mu \mathrm{M})$ & $1.705 \pm 0.187(1.39)$ & $0.972 \pm 0.131(0.80)$ \\
\hline
\end{tabular}

a/C50 values were determined by MTT assay as described in "Materials and Methods," and were obtained from three independent experiments in triplicate.

${ }^{b}$ Resistance fold (RF) was calculated from dividing the IC50 values of resistant cells (HEK293/ABCB1) by the IC50 of parental cells (HEK293/pcDNA3.1) in the presence or absence of NVP-CGM097 or positive control inhibitor.

${ }^{*} p<0.05$ vs. group treated with antineoplastic drug only.

TABLE 3 | NVP-CGM097 did not affect ABCG2-mediated MDR.

\begin{tabular}{|c|c|c|}
\hline \multirow[t]{2}{*}{ Treatment } & \multicolumn{2}{|c|}{$I C_{50} \pm S D^{a}\left(R F^{b}\right)(\mu M)$} \\
\hline & $\mathrm{NCl}-\mathrm{H} 460$ & NCI-H460/MX20 \\
\hline Mitoxantrone & $0.035 \pm 0.002(1.00)$ & $5.567 \pm 0.011(159.05)$ \\
\hline +NVP CGM097 (1 $\mu \mathrm{M})$ & $0.029 \pm 0.001(0.82)$ & $5.762 \pm 0.177(164.63)$ \\
\hline +NVP CGM097 (3 $\mu \mathrm{M})$ & $0.026 \pm 0.023(0.74)$ & $5.538 \pm 0.039(158.23)$ \\
\hline +Ko143(3 $\mu \mathrm{M})$ & $0.025 \pm 0.002(0.71)$ & $0.404 \pm 0.005(11.54)^{*}$ \\
\hline Cisplatin & $2.871 \pm 0.012(1.00)$ & $2.698 \pm 0.333(0.94)$ \\
\hline +NVP CGM097 (1 $\mu \mathrm{M})$ & $2.602 \pm 0.074(0.91)$ & $2.346 \pm 0.174(0.82)$ \\
\hline +NVP CGM097 (3 $\mu \mathrm{M})$ & $2.611 \pm 0.05(0.91)$ & $3.101 \pm 0.039(1.08)$ \\
\hline +K0143 (3 $\mu \mathrm{M})$ & $2.903 \pm 0.063(1.01)$ & $2.212 \pm 0.313(0.77)$ \\
\hline
\end{tabular}

"IC50 values were determined by MTT assay as described in "Materials and Methods," and were obtained from three independent experiments in triplicate.

${ }^{b}$ Resistance fold (RF) was calculated from dividing the IC50 values of resistant cells ( $\mathrm{NCl}$ H460/MX20) by the IC50 of parental cells (NCl-H460) in the presence or absence of NVP-CGM097 or positive control inhibitor.

${ }^{*} p<0.05$ vs. group treated with antineoplastic drug only. following the manufacturer's protocol. In brief, an equal amount of membrane vesicles was incubated in the ATPase assay buffer with or without sodium orthovanadate $\left(\mathrm{Na}_{3} \mathrm{VO}_{4}\right)$ and $\mathrm{Mg}$-ATP at $37^{\circ} \mathrm{C}$. The amount of inorganic phosphates was determined by a colorimetric method as previously described (30).

\section{$\left[{ }^{3} \mathrm{H}\right]$-Paclitaxel Accumulation and Efflux Assay}

The substrate $\left[{ }^{3} \mathrm{H}\right]$-paclitaxel was used to perform the drug accumulation and efflux assay to investigate the reversal mechanism of NVP-CGM097 as previously reported $(31,32)$. For accumulation assay, KB-3-1 and KB-C2 cells $\left(1 \times 10^{5}\right)$ were

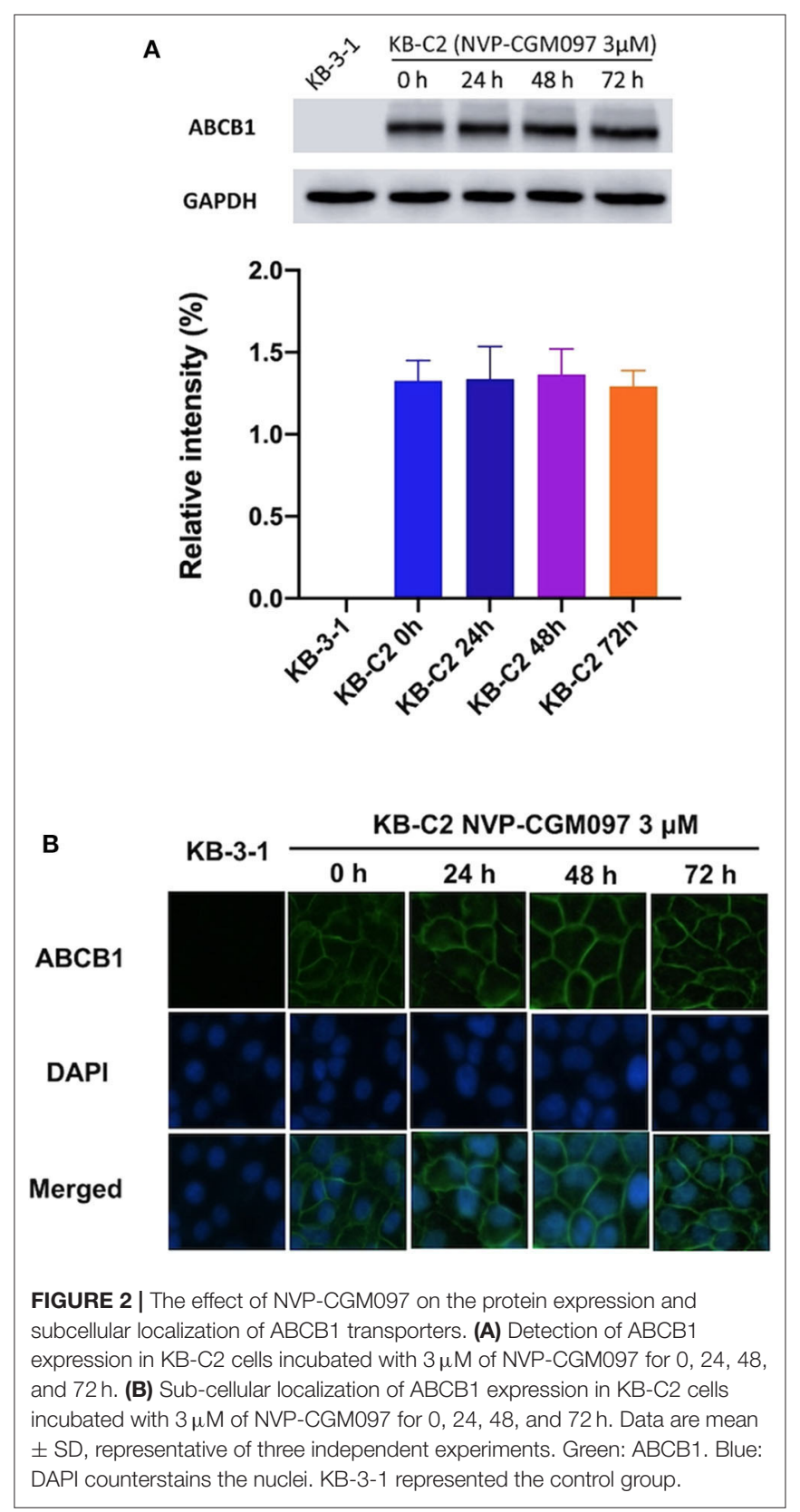


seeded in 24-well plates with overnight incubation. Different concentrations of NVP-CGM097 $(0,1,3 \mu \mathrm{M})$ and verapamil $(3 \mu \mathrm{M})$ were added in designated wells for $2 \mathrm{~h}$ following incubation with $\left[{ }^{3} \mathrm{H}\right]$-paclitaxel for another $2 \mathrm{~h}$ at $37^{\circ} \mathrm{C}$. After washing with ice-cold PBS, cells were lysed and collected in $5 \mathrm{ml}$ scintillation fluid. For efflux assay, NVP-CGM097 (0, 1, $3 \mu \mathrm{M})$ and verapamil $(3 \mu \mathrm{M})$ were added in designated wells for $2 \mathrm{~h}$ following incubation with $\left[{ }^{3} \mathrm{H}\right]$-paclitaxel for another $2 \mathrm{~h}$ at $37^{\circ} \mathrm{C}$. Subsequently, supernatant was removed and fresh drugfree medium with or without an inhibitor was added. The lysed cells were collected at various time points $(0,30,60$, and $120 \mathrm{~min})$ in $5 \mathrm{ml}$ scintillation fluid. Radioactivity of cells was determined by the Packard TRI-CARB 1900CA liquid scintillation analyzer (Packard Instrument, Downers Grove, IL, USA) (33).

\section{Molecular Docking of NVP-CGM097 With Human ABCB1 Models}

As previously mentioned, the NVP-CGM097 3-D structure was built to dock simulation with a human ABCB1 model (34). Human ABCB1 protein model 6QEX (paclitaxel bound) and 6QEE (zosuquidar bound) were obtained from RCSB Protein Data Bank. Both models are inward-facing human ABCB1 with a resolution of $3.6 \AA$ (6QEX) or $3.9 \AA$ (6QEE) (35). Calculations of the docking were achieved in AutoDock Vina (version 1.1.2) (36). AutoDockTools (ADT, version 1.5.4) was used to add hydrogen atoms and partial charges. Docking grid center coordinates were determined from the bound ligands provided in PDB files. Docking simulation and the receptor/ligand configuration was conducted using default settings. For further study and visualization, the top-scoring pose (sort by affinity score: $\mathrm{kcal} / \mathrm{mol}$ ) was identified.

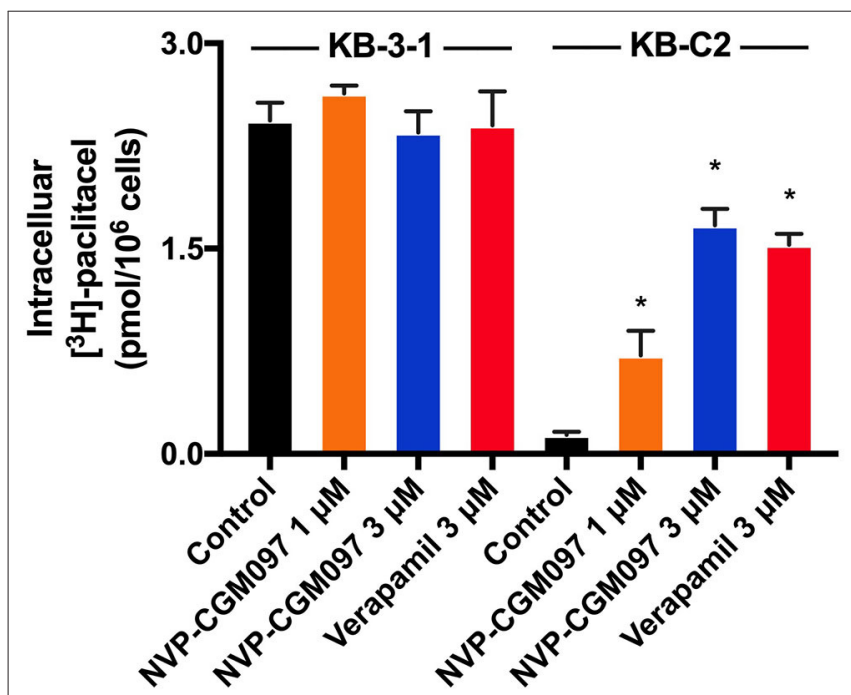

FIGURE 3 | NVP-CGM097 increased the intracellular $\left[{ }^{3} \mathrm{H}\right]$-drug accumulation in cancer cells ABCB1-overexpressing. The effect of NVP-CGM097 on the accumulation of $\left[{ }^{3} \mathrm{H}\right]$-paclitaxel in KB-3-1 and KB-C2 cells. Verapamil ( $\left.3 \mu \mathrm{M}\right)$ were used as positive controls for $\mathrm{ABCB} 1$-overexpressing cells. Data are mean $\pm \mathrm{SD}$, representative of three independent experiments. ${ }^{*} p<0.05$, compared with control group.

\section{Statistical Analysis}

The results in this study are presented as mean \pm SD and analyzed using one-way ANOVA followed by the Dunnett's test. All data was generated from at least three independent experiments with triplicates or duplicates.

\section{RESULTS}

\section{NVP-CGM097 Sensitized Chemotherapeutic Drugs in ABCB1-Overexpressing Cells}

In this study, we used NCI-H460 and its drug-selected ABCG2overexpressing cell line NCI-H460/MX20, KB-3-1 and its drug-selected ABCB1-overexpressing cell line KB-C2, SW620 cells and its drug-selected ABCB1-overexpressing cell line SW620/Ad300. Considering that drug selected cell lines have multiple factors affected their sensitivity to drugs, ABCG1 gene-transfected HEK293 cells were used to further validate the results. The cytotoxicity of NVP-CGM097 in these cell lines was first evaluated. The $\mathrm{IC}_{50}$ and $\mathrm{IC}_{20}$ of NVP-CGM097 for $\mathrm{KB}-3-1$ were 44.03 and $13.53 \mu \mathrm{M}$, respectively, for $\mathrm{KB}$ C2 were 45.54 and $11.24 \mu \mathrm{M}$, respectively, for SW620 were 25.20 and $4.23 \mu \mathrm{M}$, respectively, for SW620/Ad300 were

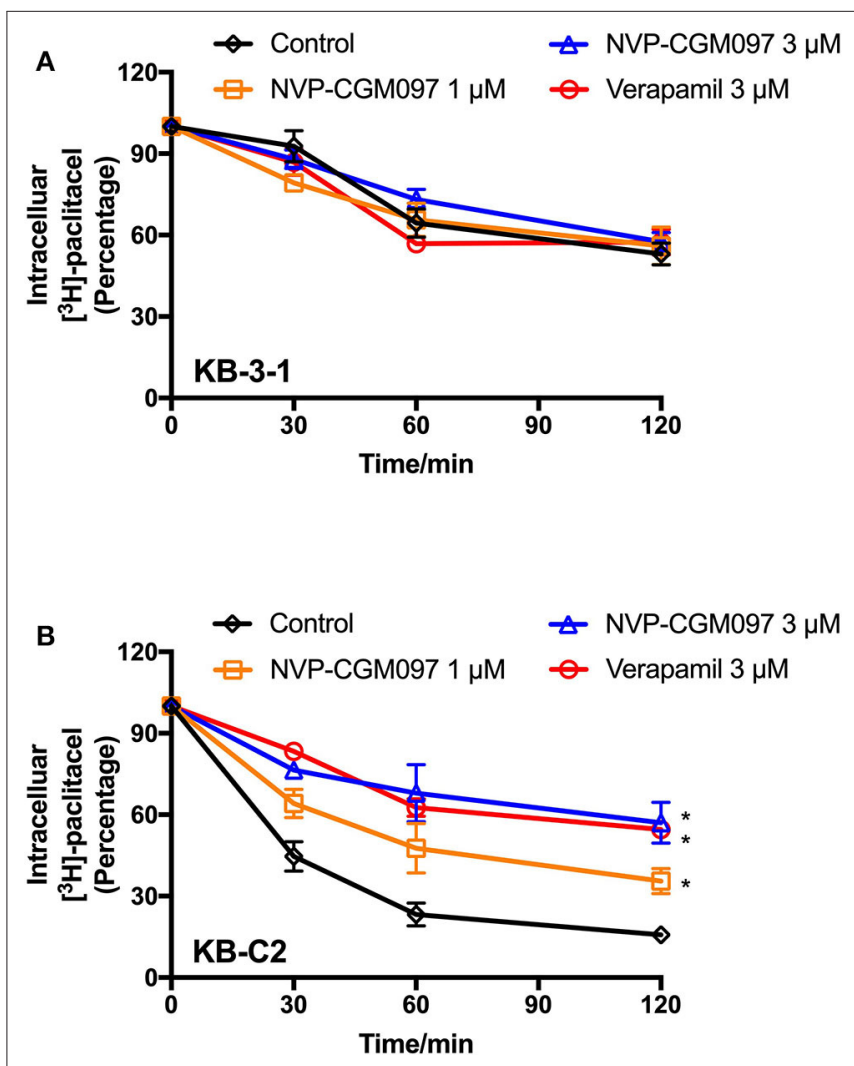

FIGURE 4 | NVP-CGM097 inhibited the efflux function of ABCB1 transporters (A,B) The effects of NVP-CGM097 on efflux of [ $\left.{ }^{3} \mathrm{H}\right]$-paclitaxel in KB-3-1 and KB-C2 cells. Data are mean $\pm \mathrm{SD}$, representative of three independent experiments. ${ }^{*} p<0.05$, compared with control group. 
17.05 and $3.82 \mu \mathrm{M}$, respectively, for HEK293/pcDNA3.1 were 14.36 and $3.99 \mu \mathrm{M}$, respectively, for HEK293/ABCB1 were 14.57 and $4.02 \mu \mathrm{M}$, respectively. We selected the concentrations in which no more than $20 \%$ cell proliferation inhibition was observed as the concentrations used in the drug combination assays. As shown in Figure 1, we chose 1 and $3 \mu \mathrm{M}$ as non-toxic concentrations in the following experiments. As shown in Table 1, co-treatments of NVP-CGM097 significantly decreased the $\mathrm{IC}_{50}$ values of doxorubicin and paclitaxel in KB-C2 and SW620/Ad300 cells as compared to the control group. In addition, the potencies of doxorubicin and paclitaxel in HEK293/ABCB1 cells were substantially increased by NVPCGM097, compared with that in the empty vector transfected HEK293/pcDNA3.1 cells (Table 2). These results indicate that NVP-CGM097 sensitized chemotherapeutic drugs in ABCB1overexpressing cells. In addition, in ABCG2 overexpressed NCIH460/MX20 cells, NVP-CGM097 did not alter the sensitivity against mitoxantrone, an ABCG2 substrate (Table 3). These results suggest that NVP-CGM097 can restore the chemosensitivity in ABCB1 overexpressing cells. Verapamil was used as a positive control in this study as a known ABCB1 inhibitor, Ko143 was used as a positive control inhibitor of ABCG2. In addition, cisplatin is used as a negative control anticancer drug as it is a non-substrate of both ABCB1 and ABCG2.

\section{NVP-CGM097 Did Not Affect the Level of Expression and Subcellular Localization of ABCB1 Protein}

Down-regulation of $\mathrm{ABC}$ transporters or relocation of them from the cell membranes to the cytoplasm has been reported to minimize MDR in cancer cells (33). To evaluate those possible mechanisms, we performed Western blotting and immunofluorescence assays on NVP-CGM097-treated ABCB1-overexpresing cells. After incubation with $3 \mu \mathrm{M}$ NVP-CGM097 for 0, 24, 48, and $72 \mathrm{~h}$, the expression of ABCB1 (170 kDa) in KB-C2 cells did not significantly change (Figure 2A). Besides, the ABCB1 transporter was retained on the cell membranes after the treatment with NVP-CGM097 for 0, 24, 48, and $72 \mathrm{~h}$ (Figure 2B). These results suggest that NVP-CGM097 treatment up to $72 \mathrm{~h}$ could not alter the expression and localization of $\mathrm{ABCB} 1$ protein. Whether NVP-CGM097 can affect ABCB1 expression level or localization after longer time treatment warrants further investigation.

\section{NVP-CGM097 Increased the Intracellular Accumulation of $\left[{ }^{3} \mathrm{H}\right]$-Paclitaxel in ABCB1-Overexpressing Cells}

To better understand how NVP-CGM097 antagonizes ABCB1mediated MDR, the $\left[{ }^{3} \mathrm{H}\right]$-paclitaxel accumulation assay was conducted. Our findings show that $3 \mu \mathrm{M}$ of NVP-CGM097 significantly increases $\left[{ }^{3} \mathrm{H}\right]$-paclitaxel intracellular accumulation in KB-C2 cells. The increasing effect of $3 \mu \mathrm{M}$ of NVPCGM097 is similar to the effect of $3 \mu \mathrm{M}$ of verapamil in ABCB1-overexpressing KB-C2 cells (Figure 3). Besides, NVPCGM097 did not affect the accumulation of parental KB-31 cells. These results indicate that NVP-CGM097 increases the intracellular accumulation of $\left[{ }^{3} \mathrm{H}\right]$-paclitaxel in $\mathrm{ABCB} 1-$ mediated MDR cells.

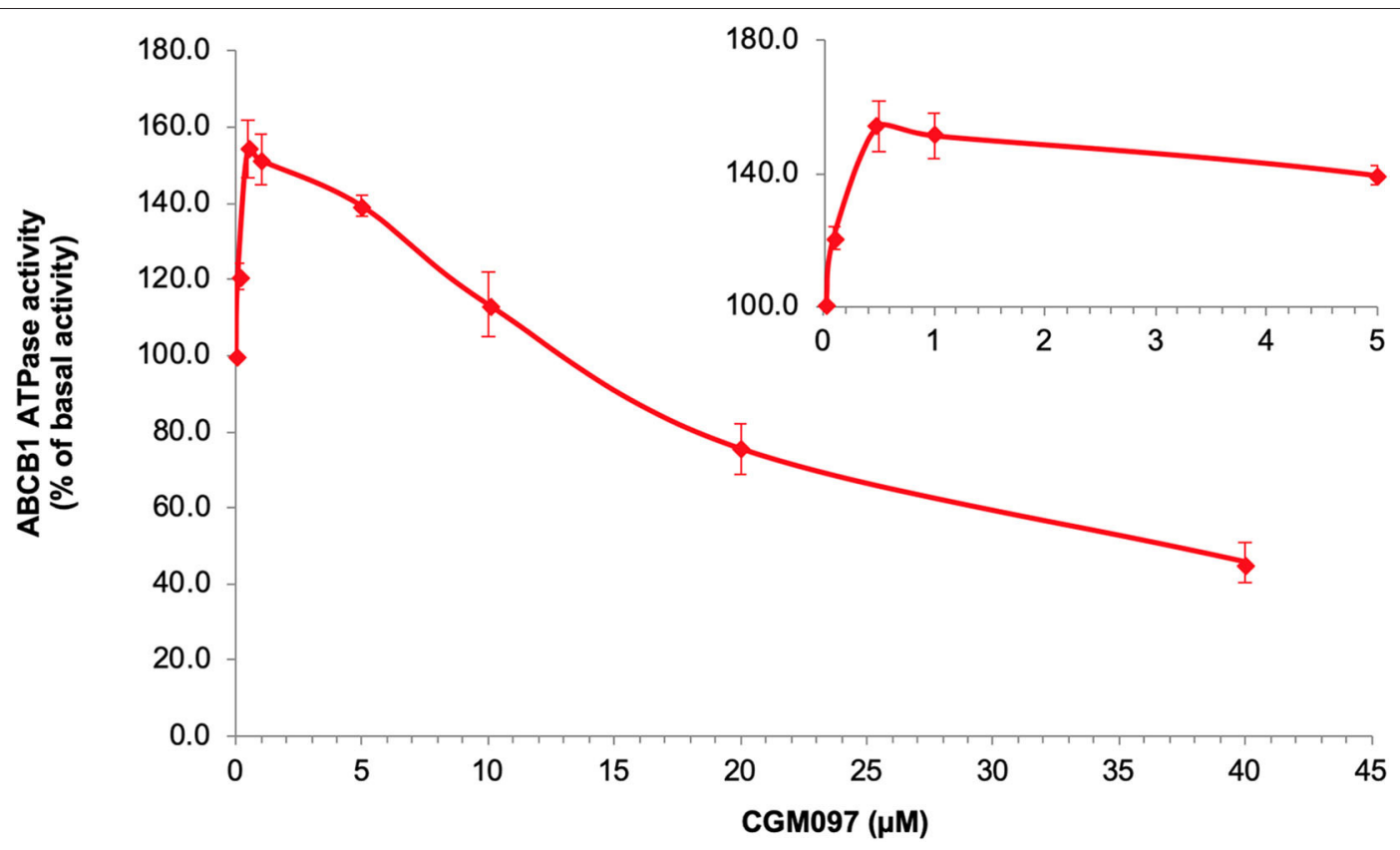

FIGURE 5 | NVP-CGM097 stimulate first and then inhibit the ATPase activity of ABCB1. Effect of various concentrations of NVP-CGM097 on the ATPase activity of ABCB1. The inset graphs illustrate the effect of 0-4 $\mu$ M NVP-CGM097 on the ATPase activity of ABCB1. Data are mean \pm SD, representative of three independent experiments. 


\section{NVP-CGM097 Inhibited the Efflux of $\left[{ }^{3} \mathrm{H}\right]$-Paclitaxel in ABCB1-Overexpressing Cells}

Since there are multiple factors (either increase drug uptake or decrease drug efflux) that can result in increased paclitaxel accumulation, we explored whether NVP-CGM097 can inhibit the efflux function of ABCB1. The efflux assay was performed to further examine the dynamic process of resistant cancer cells re-sensitization by treatment of NVP-CGM097. As shown in Figure 4, NVP-CGM097 did not alter the $\left[{ }^{3} \mathrm{H}\right]$-paclitaxel efflux in parental KB-3-1 cells. However, the $\left[{ }^{3} \mathrm{H}\right]$-paclitaxel efflux activity was significantly decreased by treatment of NVP-CGM097. The obtained results showed that NVP-CGM097 can block the efflux activity of $\mathrm{ABCB} 1$-overexpressing cells, therefore, increasing intracellular paclitaxel accumulation.

\section{The Effect of NVP-CGM097 on ABCB1 ATPase Activities}

We tested ABCB1-mediated ATP hydrolysis in membrane vesicles after incubation at various NVP-CGM097 concentrations $(0-40 \mu \mathrm{M})$, to further assess the influence of NVP-CGM097 on ABCB1 ATPase operation. According to the result (Figure 5), NVP-CGM097 stimulated the ABCB1-associated ATPase to a maximum of $154.3 \%$ of the basal activity at concentration range of $0-1 \mu \mathrm{M}$ and NVP-CGM097's stimulatory impact reached a limit of 50 per cent (EC50) at $0.45 \mu \mathrm{M}$. In addition, at higher concentration, NVP-CGM097 showed inhibitory effect to the ATPase of ABCB1.

\section{Docking Simulation of NVP-CGM097 in the Drug-Binding Pocket of Human ABCB1}

In the above result of ATPase assay, NVP-CGM097 displayed stimulating effect at lower concentration while inhibitory effect at higher concentration on ATPase. We applied docking simulation in both the ATPase-stimulator (substrate) binding site (6QEX) and the ATPase-inhibitor binding site (6QEE) of ABCB1 protein. The results showed that NVP-CGM097 docked into the substrate and inhibitory binding site with an affinity score of -8.5 $\mathrm{kcal} / \mathrm{mol}$ and $-10.2 \mathrm{kcal} / \mathrm{mol}$, respectively. Details of ligandreceptor interaction was displayed in Figure 6. The primary factor leading to the binding of NVP-CGM097 to the ABCB1 protein for substratum binding sites is through hydrophobic interactions. NVP-CGM097 is positioned and stabilized in the hydrophobic cavity formed by Tyr310, Tyr307, Ile306, Phe303, Ile340, Phe343, and Ala871. Additionally, the oxopiperazin group of NVP-CGM097 was stabilized by a hydrogen bond formed with Gln990. For inhibitor binding site, the oxodihydroisoquinoline group of NVP-CGM097 was stabilized via hydrogen bond with Gln724. Besides, NVP-CGM097 was also stabilized by hydrophobic interaction in the cavity formed by Phe302, Ile305, Tyr309, Tyr306, Ile339, Phe342, Phe769, Phe993, and Ala986.

\section{DISCUSSION}

MDR is the main reason for the failure of drug treatment in cancer therapy. One of the most fundamental reasons of

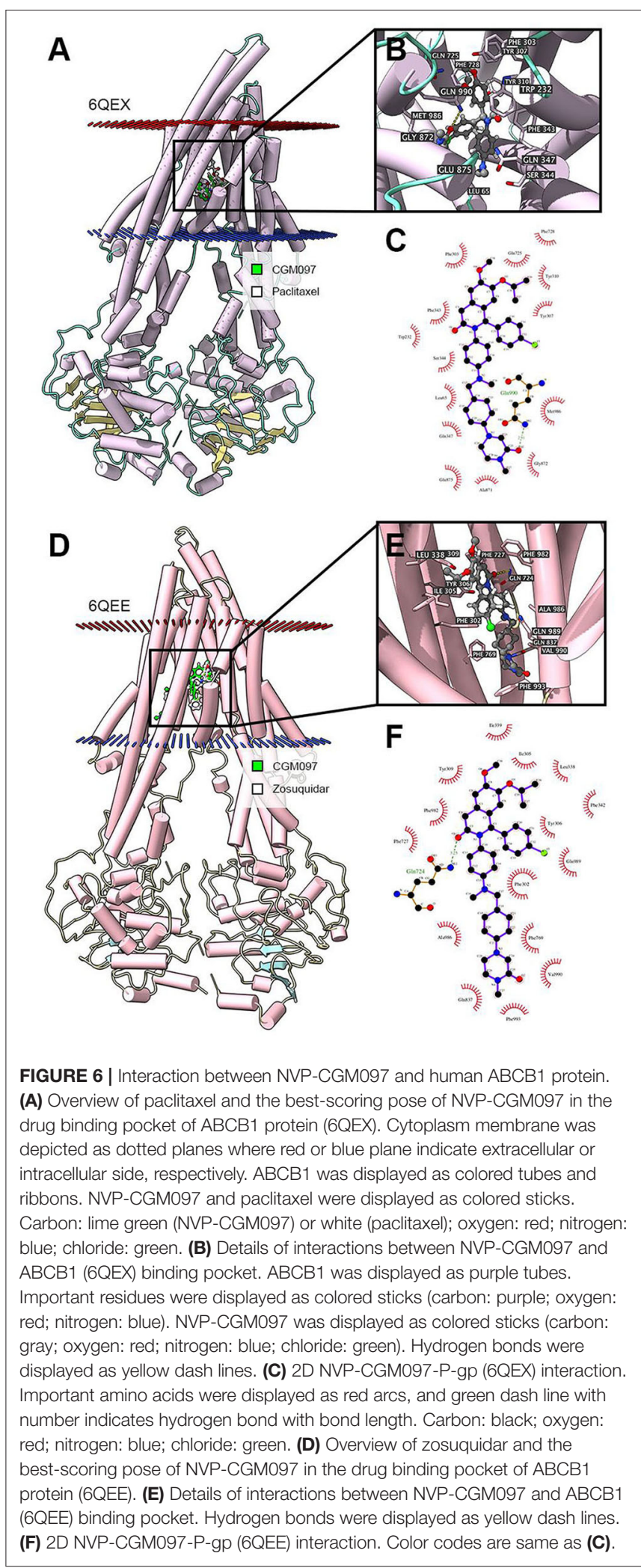

MDR is the overexpression of ABCB1 (13). Screening ABCB1 inhibitors is one of the strategies to reverse $\mathrm{ABCB} 1$-mediated MDR. ABCB1 inhibitors reverse MDR by inhibiting $A B C B 1$ 
transporter efflux activity or by down-regulating $\mathrm{ABCB} 1$ protein expression, reducing the efflux of chemotherapeutic drugs and therefore increasing drug accumulation in tumor cells $(37,38)$. The common reasons for lack of $\mathrm{ABCB} 1$-reversal agents involve low level drug selectivity, weak targeting, excessive initial dose, large adverse reactions, and unclear pharmacokinetic process in vivo et al. (39). Therefore, it could be a better strategy to reevaluate clinically available drugs with known pharmacokinetic and pharmacodynamics profiles, which can be re-purposed as ABCB1-mediated reversal agents of MDR.

NVP-CGM097 is an HDM2 inhibitor that can interrupt the binding of HDM2-p53 to release wild-type p53, thereby activating p53 and leading to cell apoptosis (40). Phase I clinical trials using NVP-CGM097 is now under way for the treatment of WT-p53 solid tumors. Besides, the combination of NVP-CGM097 with other clinically available drugs such as 5fluoroucracil, temozolomide, or everolimus (RAD001) showed additive antiproliferative effects in neuroendocrine tumor cell line GOT1 cells, in particular, the co-incubation with 5fluoroucracil also increased p53 and p21 expression in an additive manner (41). In addition, the combination of AEB071 (protein kinase C inhibitors) and NVP-CGM097 resulted in tumor stasis or regression (42). There is currently no research on the effects of NVP-CGM097 on MDR mediated by ABCB1. To our knowledge, this article may be the first to report the inhibition activity of NVP-CGM097 against ABCB1. In this study, we started with the investigation of the toxicity of NVP-CGM097 in ABCB1overexpressing cells by MTT assay. Based on the proliferation curves of inhibitory rate, we selected the concentration of NVP-CGM097 in which proliferation inhibitory rate was $<20 \%$ for combinational studies. It was found that the $\mathrm{IC}_{50}$ values of doxorubicin and paclitaxel in ABCB1-overexpressing cells was decreased significantly after co-administration with NVPCGM097, suggesting that NVP-CGM097 can reverse the MDR of drug-resistant cells in a concentration-dependent manner. Subsequently, the mechanism of NVP-CGM097 reversing MDR was studied. Given that $\mathrm{ABC}$ transporters are important membrane proteins mainly for uptake and expulsion of a variety of substrates, suppressing the efflux function of $\mathrm{ABCB} 1$ transporter may help to increase the concentration of chemotherapeutic drugs in ABCB1-Overexpressing tumor cells, and consequently improving the cell-killing efficacy (43). In this study, $\left[{ }^{3} \mathrm{H}\right]$-paclitaxel accumulation and efflux assay verified that NVP-CGM097 could boost the intracellular accumulation of $\mathrm{ABCB} 1$-substrate chemotherapeutic drugs in $\mathrm{ABCB} 1$-overexpressing cells by blocking the efflux function of ABCB1.

The function of ABC transporters is energized by ATPase mediated ATP hydrolysis (44). In our study, NVP-CGM097 stimulated ABCB1-ATPase when the concentration is lower than $10 \mu \mathrm{M}$ and inhibited ABCB1-associated ATPase at higher concentration of NVP-CGM097. Previous studies have also shown that some ABCB1 inhibitors could either stimulate (45), inhibit (46), or show stimulatory effect at lower concentration while inhibitory effect at higher concentration (47). Such discrimination in ABCB1 inhibitors were explained recently by Alam et al. through a set of substrate- and inhibitor-binding human ABCB1 cryo-EM protein models (35). Thus, we performed molecular docking simulation in both models to further illustrate the interaction. According to our docking results, NVP-CGM097 had good binding affinity in both substrate and inhibitor-binding ABCB1 models. NVP-CGM097 likely occupied substrate-binding pocket thus stimulated $\mathrm{ABCB} 1$-associated ATPase at lower concentration, while with the concentration increasing, NVP-CGM097 tended to bind to the inhibitory site, which led to slight but critical conformational changes in the transporter and reduced the ATPase activity. Such conformational change could be the shift of transmembrane domain, resulting in increased distance between nucleotide binding domains (35).

The reversal of ABCB1-mediated MDR can be accomplished either by suppressing the ABCB1 efflux process or downregulating the $\mathrm{ABCB} 1$ expression. This research then explored the impact of NVP-CGM097 on the degree of expression and subcellular localization of ABCB1 protein. The findings indicated that NVP-CGM097 did not affect the protein expression and subcellular localization of ABCB1 upon incubation with NVP-CGM097. Further study is needed whether long time NVP-CGM097 treatment could affect the expression and/or localization of ABCB1.

In conclusion, this study demonstrates that NVP-CGM097 can reverse the MDR in ABCB1-overexpressing cancer cells through blocking the function of ABCB1 transporter. NVPCGM097 inhibits the efflux function of the ABCB1 transporter, which in turn increases the intracellular accumulation of chemotherapeutic drugs to induce augmented cytotoxicity effects. These results suggest that the usage of NVP-CGM097 would have the potential to be expanded as a combinational therapy with chemotherapeutic drugs in treating solid tumors. Patients bearing ABCB1-overexpressed tumors may benefit from NVP-CGM097 combinational chemotherapy.

\section{DATA AVAILABILITY STATEMENT}

The original contributions presented in the study are included in the article/supplementary material, further inquiries can be directed to the corresponding author/s.

\section{AUTHOR CONTRIBUTIONS}

ZS-C, X-QL, and JL designed the experiments. MZ and X-YC performed the experiments and wrote the paper. X-DD, WF, J-QW, and Q-XT performed the experiments. QC analyzed the data. All authors read and approved the final manuscript.

\section{FUNDING}

This work was supported by the National Natural Science Foundation of China (No. 81473687), the Academic Promotion Program of Shandong First Medical University, China (No. 2019QL017), and High-level Project Cultivation Program of Shandong First Medical University, China (No. 2018GCC14). 
MZ thanks China Scholarship Council for reimbursing daily expenditures in the United States of America.

\section{ACKNOWLEDGMENTS}

The authors thank Chemie Tek for kindly provided NVPCGM097. We thank Dr. Shin-ichi Akiyama (Kagoshima

\section{REFERENCES}

1. Oliner J, Kinzler KW, Meltzer P, George DL, Vogelstein B. Amplification of a gene encoding a p53-associated protein in human sarcomas. Nature. (1992) 358:80-3. doi: 10.1038/358080a0

2. Szakács G, Paterson JK, Ludwig JA, Booth-Genthe C, Gottesman MM. Targeting multidrug resistance in cancer. Nat Rev Drug Discov. (2006) 5:21934. doi: $10.1038 / \mathrm{nrd} 1984$

3. Kartal-Yandim M, Adan-Gokbulut A, Baran Y. Molecular mechanisms of drug resistance and its reversal in cancer. Crit Rev Biotechnol. (2016) 36:71626. doi: 10.3109/07388551.2015.1015957

4. Binkhathlan Z, Lavasanifar A. P-glycoprotein inhibition as a therapeutic approach for overcoming multidrug resistance in cancer: current status and future perspectives. Curr Cancer Drug Targets. (2013) 13:326-46. doi: 10.2174/15680096113139990076

5. Dean M, Hamon Y, Chimini G. The human ATP-binding cassette (ABC) transporter superfamily. J Lipid Res. (2001) 42:1007-17. doi: 10.1101/gr.GR-1649R

6. Sun YL, Patel A, Kumar P, Chen Z-S. Role of ABC transporters in cancer chemotherapy. China J Cancer. (2012) 31:51. doi: 10.5732/cjc.011.10466

7. Yin Y, Li W, Deng M, Zhang P, Shen Q, Wang G, et al. Extracellular high mobility group box chromosomal protein 1 promotes drug resistance by increasing the expression of P-glycoprotein expression in gastric adenocarcinoma cells. Mol Med Rep. (2014) 9:1439-43. doi: 10.3892/mmr.2014.1961

8. Tomono T, Kajita M, Yano K, Ogihara T. Adenovirus vector infection of non-small-cell lung cancer cells is a trigger for multi-drug resistance mediated by P-glycoprotein. Biochem Biophys Res Commun. (2016) 476:183-7. doi: 10.1016/j.bbrc.2016.05.070

9. Tang Y, Wang Y, Deosarkar S, Soroush F, Kiani MF, Wang B. Fast, stable induction of P-glycoprotein-mediated drug resistance in BT-474 breast cancer cells by stable transfection of ABCB1 gene. Anticancer Res. (2015) 35:2531-8.

10. Chen Y, Zhang L, Lu X, Wu K, Zeng J, Gao Y, et al. Sinomenine reverses multidrug resistance in bladder cancer cells via P-glycoprotein-dependent and independent manners. Pharmazie. (2014) 69:48-54.

11. Kato T, Mizutani K, Kameyama K, Kawakami K, Fujita Y, Nakane K, et al. Serum exosomal P-glycoprotein is a potential marker to diagnose docetaxel resistance and select a taxoid for patients with prostate cancer. Urol Oncol. (2015) 33:385.e315-20. doi: 10.1016/j.urolonc.2015.04.019

12. Cheng C, Liu ZG, Zhang H, Xie JD, Chen XG, Zhao XQ, et al. Enhancing chemosensitivity in ABCB1-and ABCG2-overexpressing cells and cancer stem-like cells by an aurora kinase inhibitor CCT129202. Mol Pharm. (2012) 9:1971-82. doi: 10.1021/mp2006714

13. Zhou SF. Structure, function and regulation of P-glycoprotein and its clinical relevance in drug disposition. Xenobiotica. (2008) 38:802-32. doi: 10.1080/00498250701867889

14. Li W, Zhang H, Assaraf YG, Zhao K, Xu X, Xie J, et al. Overcoming $\mathrm{ABC}$ transporter-mediated multidrug resistance: molecular mechanisms and novel therapeutic drug strategies. Drug Resist Updat. (2016) 27:14-29. doi: 10.1016/j.drup.2016.05.001

15. Sachs J, Döhl K, Weber A, Bonus M, Blesse F, Fleischer E, et al. Novel 3, 4dihydroisocoumarins inhibit human P-gp and BCRP in multidrug resistant tumors and demonstrate substrate inhibition of yeast Pdr5. Front Pharmacol. (2019) 10:400. doi: 10.3389/fphar.2019.00400

16. Sinha BK, Perera L, Cannon RE. Reversal of drug resistance by JS$\mathrm{K}$ and nitric oxide in $\mathrm{ABCB} 1$-and $\mathrm{ABCG} 2$-expressing multi-drug
University, Kagoshima, Japan) for providing the KB-3-1 and KBC2 cells. We thank Drs. Susan Bates and Robert Robey (NCI, NIH, MD) for providing NCI-H460, NCI-H460/MX20, SW620, SW620/Ad300, HEK293/pcDNA3.1, and ABCB1-transfected HEK/ABCB1 cell lines. We thank Dr. Dong-Hua Yang (St. John's University) and Dr. Yun-Kai Zhang (Vanderbilt University) for language editing.

resistant human tumor cells. Biomed Pharmacother. (2019) 120:109468. doi: 10.1016/j.biopha.2019.109468

17. Holzer P, Masuya K, Furet P, Kallen J, Valat-Stachyra T, Ferretti SP, et al. Discovery of a dihydroisoquinolinone derivative (NVP-CGM097): a highly potent and selective MDM2 inhibitor undergoing phase 1 clinical trials in p53wt tumors. J Med Chem. (2015) 58:6348-58. doi: 10.1021/acs.jmedchem.5b00810

18. Thomas H, Coley HM. Overcoming multidrug resistance in cancer: an update on the clinical strategy of inhibiting p-glycoprotein. Cancer Control. (2003) 10:159-65. doi: 10.1177/107327480301000207

19. Chen L, Zhao Y, Halliday G, Berry P, Rousseau R, Middleton S, et al. Structurally diverse MDM2-p53 antagonists act as modulators of MDR-1 function in neuroblastoma. Br J Cancer. (2014) 111:716-25. doi: $10.1038 /$ bjc. 2014.325

20. Fan $\mathrm{Y}, \mathrm{Ma} \mathrm{K}$, Jing J, Wang $\mathrm{C}, \mathrm{Hu} \mathrm{Y}$, Shi $\mathrm{Y}$, et al. Recombinant dual-target MDM2/MDMX inhibitor reverses doxorubicin resistance through activation of the TAB1/TAK1/p38 MAPK pathway in wild-type p53 multidrug-resistant breast cancer cells. J Cancer. (2020) 11:25. doi: 10.7150/jca.32765

21. Valat T, Masuya K, Baysang F, Albrecht G, Buschmann N, Erdmann D, et al. Mechanistic Study of NVP-CGM097: A Potent, Selective and Species Specific Inhibitor of p53-Mdm2. San Diego, CA: AACR (2014).

22. Jeay S, Gaulis S, Ferretti S, Bitter H, Ito M, Valat T, et al. A distinct p53 target gene set predicts for response to the selective p53-HDM2 inhibitor NVP-CGM097. Elife. (2015) 4:e06498. doi: 10.7554/eLife.06498.021

23. Akiyama S-I, Fojo A, Hanover JA, Pastan I, Gottesman MM. Isolation and genetic characterization of human $\mathrm{KB}$ cell lines resistant to multiple drugs. Somat Cell Mol Genet. (1985) 11:117-26. doi: 10.1007/BF01534700

24. Lyall RM, Hwang J, Cardarelli C, FitzGerald D, Akiyama S-I, Gottesman $\mathrm{MM}$, et al. Isolation of human KB cell lines resistant to epidermal growth factor-Pseudomonas exotoxin conjugates. Cancer Res. (1987) 47:2961-6.

25. Lai GM, Chen YN, Mickley LA, Fojo AT, Bates SE. P-glycoprotein expression and schedule dependence of adriamycin cytotoxicity in human colon carcinoma cell lines. Int J Cancer. (1991) 49:696-703. doi: 10.1002/ijc.2910490512

26. Robey RW, Honjo Y, van de Laar A, Miyake K, Regis JT, Litman T, et al. A functional assay for detection of the mitoxantrone resistance protein, MXR (ABCG2). Biochim Biophys Acta. (2001) 1512:171-82. doi: 10.1016/S0005-2736(01)00308-X

27. Fung KL, Pan J, Ohnuma S, Lund PE, Pixley JN, Kimchi-Sarfaty C, et al. MDR1 synonymous polymorphisms alter transporter specificity and protein stability in a stable epithelial monolayer. Cancer Res. (2014) 74:598-608. doi: 10.1158/0008-5472.CAN-13-2064

28. Zhang GN, Zhang YK, Wang YJ, Barbuti AM, Zhu XJ, Yu XY, et al. Modulating the function of ATP-binding cassette subfamily G member 2 (ABCG2) with inhibitor cabozantinib. Pharmacol Res. (2017) 119:89-98. doi: 10.1016/j.phrs.2017.01.024

29. Zhang W, Fan YF, Cai CY, Wang JQ, Teng QX, Lei ZN, et al. Olmutinib (BI1482694/HM61713), a novel epidermal growth factor receptor tyrosine kinase inhibitor, reverses ABCG2-mediated multidrug resistance in cancer cells. Front Pharmacol. (2018) 9:1097. doi: 10.3389/fphar.2018.01097

30. Wang JQ, Wang B, Lei ZN, Teng QX, Li JY, Zhang W, et al. Derivative of 5-cyano-6-phenylpyrimidin antagonizes ABCB1-and ABCG2mediated multidrug resistance. Eur J Pharmacol. (2019) 863:172611. doi: 10.1016/j.ejphar.2019.172611

31. Fan YF, Zhang W, Zeng L, Lei ZN, Cai CY, Gupta P, et al. Dacomitinib antagonizes multidrug resistance (MDR) in cancer cells by inhibiting the 
efflux activity of ABCB1 and ABCG2 transporters. Cancer Lett. (2018) 421:186-98. doi: 10.1016/j.canlet.2018.01.021

32. Ji N, Yang Y, Cai CY, Lei ZN, Wang JQ, Gupta P, et al. Selonsertib (GS4997), an ASK1 inhibitor, antagonizes multidrug resistance in ABCB1and ABCG2-overexpressing cancer cells. Cancer Lett. (2019) 440:82-93. doi: 10.1016/j.canlet.2018.10.007

33. Cai CY, Zhang W, Wang JQ, Lei ZN, Zhang YK, Wang YJ, et al. Biological evaluation of non-basic chalcone CYB-2 as a dual ABCG2/ABCB1 inhibitor. Biochem Pharmacol. (2020) 175:113848. doi: 10.1016/j.bcp.2020. 113848

34. Wang JQ, Li JY, Teng QX, Lei ZN, Ji N, Cui Q, et al. Venetoclax, a BCL2 inhibitor, enhances the efficacy of chemotherapeutic agents in wild-type ABCG2-overexpression-mediated MDR cancer cells. Cancers. (2020) 12:466. doi: $10.3390 /$ cancers 12020466

35. Alam A, Kowal J, Broude E, Roninson I, Locher KP. Structural insight into substrate and inhibitor discrimination by human P-glycoprotein. Science. (2019) 363:753-6. doi: 10.1126/science.aav7102

36. Trott O, Olson AJ. AutoDock vina: improving the speed and accuracy of docking with a new scoring function, efficient optimization, and multithreading. J Comput Chem. (2010) 31:455-61. doi: 10.1002/jcc.21334

37. Zhu Y, Liu C, Nadiminty N, Lou W, Tummala R, Evans CP, et al. Inhibition of ABCB1 expression overcomes acquired docetaxel resistance in prostate cancer. Mol Cancer Ther. (2013) 12:1829-36. doi: 10.1158/1535-7163.MCT-13-0208

38. Gupta P, Garg T, Tanmay M, Arora S. Polymeric drug-delivery systems: role in P-gp efflux system inhibition. Crit Rev Ther Drug Carrier Syst. (2015) 32:247-75. doi: 10.1615/CritRevTherDrugCarrierSyst.20150 11592

39. McDevitt CA, Callaghan R. How can we best use structural information on P-glycoprotein to design inhibitors? Pharmacol Ther. (2007) 113:429-41. doi: 10.1016/j.pharmthera.2006.10.003

40. Wang Z, Zhan Y, Xu J, Wang Y, Sun M, Chen J, et al. $\beta$-sitosterol reverses multidrug resistance via BCRP suppression by inhibiting the p53-MDM2 interaction in colorectal cancer. J Agric Food Chem. (2020) 68:3850-8. doi: 10.1021/acs.jafc.0c00107

41. Reuther C, Heinzle V, Nölting S, Herterich S, Hahner S, Halilovic E, et al. The HDM2 (MDM2) inhibitor NVP-CGM097 inhibits tumor cell proliferation and shows additive effects with 5-fluorouracil on the p53-p21$\mathrm{Rb}-\mathrm{E} 2 \mathrm{~F} 1$ cascade in the p53wild type neuroendocrine tumor cell line GOT1. Neuroendocrinology. (2018) 106:1-19. doi: 10.1159/000453369

42. Carita G, Frisch-Dit-Leitz E, Dahmani A, Raymondie C, Cassoux N, PipernoNeumann S, et al. Dual inhibition of protein kinase C and p53-MDM2 or PKC and $\mathrm{mTORC} 1$ are novel efficient therapeutic approaches for uveal melanoma. Oncotarget. (2016) 7:33542. doi: 10.18632/oncotarget.9552

43. Chen T, Wang C, Liu Q, Meng Q, Sun H, Huo X, et al. Dasatinib reverses the multidrug resistance of breast cancer MCF-7 cells to doxorubicin by downregulating P-gp expression via inhibiting the activation of ERK signaling pathway. Cancer Biol Ther. (2015) 16:106-14. doi: 10.4161/15384047.2014.987062

44. Cui Q, Wang J-Q, Assaraf YG, Ren L, Gupta P, Wei L, et al. Modulating ROS to overcome multidrug resistance in cancer. Drug Resist Updat. (2018) 41:1-25. doi: 10.1016/j.drup.2018.11.001

45. Ji N, Yang Y, Cai C-Y, Lei Z-N, Wang J-Q, Gupta P, et al. VS-4718 antagonizes multidrug resistance in ABCB1-and ABCG2-overexpressing cancer cells by inhibiting the efflux function of ABC transporters. Front Pharmacol. (2018) 9:1236. doi: 10.3389/fphar.2018.01236

46. Ji N, Yang Y, Cai C-Y, Wang J-Q, Lei Z-N, Wu Z-X, et al. Midostaurin reverses ABCB1-mediated multidrug resistance, an in vitro study. Front Oncol. (2019) 9:514. doi: 10.3389/fonc.2019.00514

47. Sarkadi B, Price EM, Boucher RC, Germann UA, Scarborough GA. Expression of the human multidrug resistance cDNA in insect cells generates a high activity drug-stimulated membrane ATPase. J Biol Chem. (1992) 267:4854-8.

Conflict of Interest: The authors declare that the research was conducted in the absence of any commercial or financial relationships that could be construed as a potential conflict of interest.

Copyright (๑ 2020 Zhang, Chen, Dong, Wang, Feng, Teng, Cui, Li, Li and Chen. This is an open-access article distributed under the terms of the Creative Commons Attribution License (CC BY). The use, distribution or reproduction in other forums is permitted, provided the original author(s) and the copyright owner(s) are credited and that the original publication in this journal is cited, in accordance with accepted academic practice. No use, distribution or reproduction is permitted which does not comply with these terms. 